\title{
Essa Boneca Tem Manual: práticas de si, discursos e legitimidades entre travestis iniciantes
}

Marília dos Santos Amaral. Faculdade Cesusc, Santa Catarina

Maria Juracy Filgueiras Toneli. Universidade Federal de Santa Catarina

\section{Resumo}

Este artigo discute os modos pelos quais os corpos se produzem como campo de saber e de práticas de si na experiência de travestis iniciantes. Por meio de pesquisa etnográfica são analisadas as atuais formas usadas pelas jovens para acessar informações, aprender técnicas, comprovar práticas e compartilhar saberes sobre as múltiplas possibilidades de experienciar as travestilidades. Os passos seguidos pelas novatas que desejam tornar-se travesti são problematizados pela perspectiva de análise discursiva proposta por Michel Foucault, trazendo ao debate as formas com que reiteram normas com o uso de hormônios e na idealização da feminilidade; e também subvertem práticas atribuindo à internet a função de aliada nas transformações. Neste estudo, são discutidas as estratégias de resistência reinventadas pelas iniciantes diante das violências exercidas pelas travestis mais experientes, assim como a persistência com que buscam produzirem-se como sujeitos legítimos das travestilidades.

Palavras-chave: corpo; discurso; mulher trans; jovens.

\section{Abstract}

This Doll Has a Handbook: practices of oneself among trans women. This article discusses the means through which bodies are produced as a field of knowledge and practices of oneself, based on the experience of beginners trans women. Based on ethnographic research, the contemporaneous ways of accessing information, learning techniques, verifying practices and sharing knowledge about the several possibilities of experiencing travestilities are analyzed. The steps followed by beginners that wish to become trans women are problematized by the perspective of discursive analysis proposed by Michel Foucault, arising the debate about the ways they reiterate guidelines with the use of hormones and the idealization of femininity, as well as subvert practices, attributing to internet the role of ally as regards transformation. This study also discusses strategies of resistance reinvented by beginners against the violence exerted by the most experienced trans women, as well as the persistence through which they try to produce themselves as legitimate subjects of travestilities.

Keywords: body; discourse; trans woman; young adults.

\section{Resumen}

Esa Muñeca Tiene Manual: prácticas de símismo entre mujeres trans. Este artículo discute los modos por los cuales los cuerpos se producen como campo de saber y de prácticas de sí mismo, en la experiencia de mujeres trans recién iniciadas. Por una investigación etnográfica son analizadas las actuales formas usadas por las jóvenes para acceder a información, aprender técnicas, comprobar prácticas y compartir saberes sobre las múltiples posibilidades de experimentar las travestilidades. Los pasos seguidos son problematizados por la perspectiva de análisis discursivo propuesta por Michel Foucault, trayendo a la discusión las formas con que repiten normas con el uso de hormonas y en la idealización de feminidad; y también aparecen prácticas atribuyendo a internet la función de aliada en las transformaciones. En este estudio, también son discutidas las estrategias de resistencia reinventadas por las novatas delante de las violencias, así como la perseverancia con que buscan producirse como sujetos legítimos de las travestilidades.

Palabras clave: cuerpo; discurso; mujer trans; jóvenes. 
"Não se nasce travesti, torna-se uma. E pra isso precisamos todos os dias aprender, experimentar e fazer tudo de novo, todo dia, todo dia" (Fala de uma jovem de 17 anos registrada em diário de campo, set./2011). Ainda que a participante desta pesquisa e autora desta frase desconheça a história de lutas do feminismo, ao ouvi-la, rapidamente a aproximamos ao aforismo emblemático "não se nasce mulher, torna-se mulher", enunciado por Simone de Beauvoir (Beauvoir, 1949/1980). No entanto, essa constatação sobre sua própria experiência é enunciada por uma das jovens durante a pesquisa que deu origem ao presente artigo que discute os saberes, discursos e as práticas de si na experiência de travestis iniciantes.

Para a realização desta pesquisa etnográfica que analisa o discurso produzido por jovens travestis e trans ${ }^{1}$, com idades entre 15 e 21 anos, foram feitas observações participantes, entrevistas e registros em diário de campo no período de três meses, com encontros semanais em diferentes espaços e momentos, ou seja, durante duas atividades em uma organização não-governamental de direitos humanos, direcionada a mulheres travestis e transexuais, e em cinco visitas em uma pensão onde quatro jovens travestis residiam, e durante dois passeios, por espaços públicos da cidade como, ruas, praça, shopping e praia.

Os discursos analisados foram enunciados por seis jovens vindas de municípios do interior da região sul do país, residentes da mesma pensão e em fase inicial do processo de transformação corporal, para alcançarem o que reconhecem como travestilidade. Estes discursos foram enunciados durante as visitas semanais realizadas uma vez por semana (cinco encontros), com duração de quatro horas à pensão nas quais foram feitas seis entrevistas individuais, gravadas em áudio e entrevistas coletivas registradas em diário de campo. Todas as travestis entrevistadas estavam pela primeira vez na cidade e exerciam a prostituição em espaços orientados pela dona da pensão.

Durante as observações participantes acompanhamos a emergência de importantes pistas para se pensar o campo das experiências trans: como e onde se aprende a ser travesti? O que é necessário saber e fazer? Quem ensina? Serão reconhecidas como travesti pelas outras? Como serão vistas pelos outros na rua? A partir dessas pistas oferecidas pelas jovens durante entrevistas realizadas sobre suas experiências de transformação corporal, dedicamo-nos a percorrer, conhecer e reconhecer as regras, normas e práticas que regem a produção dos corpos travestis. Buscamos mapear a rede de discursos que as tornam sujeitos legítimos e ilegítimos da travestilidade.
Para pensarmos o campo das sexualidades e dos gêneros em relação com os discursos, fundamentamo-nos na perspectiva de Michel Foucault e Judith Butler, em que o discurso é entendido como um conjunto de enunciados que podem pertencer a campos diferentes, mas que obedecem, apesar de tudo, a regras de funcionamento comuns com dispositivos que sustentam ou até mesmo engendram práticas (Foucault, 1969/2002a).

Neste artigo, a análise de discurso é composta pelos registros em diário de campo e pelas entrevistas com as jovens travestis iniciantes, nas quais são enunciadas as formas de relação consigo, com os procedimentos e as técnicas pelas quais são produzidas e (re)elaboradas as travestilidades. Desta forma, por meio de uma análise do discurso proposta por Michel Foucault tentamos fazer que os discursos compostos pelos enunciados possam falar por si, apresentando os exercícios pelos quais o próprio sujeito se dá como objeto por conhecer, bem como as práticas que permitam transformar seu modo de ser (Foucault, 1984/2007a).

\section{O corpo como saber e prática de si}

\author{
"Tudo o que tenho de verdadeiro são meus senti- \\ mentos e os litros de silicone que me pesam \\ toneladas". (Agrado, Trecho do filme Tudo Sobre \\ Minha Mãe).
}

Assim como fez a jovem autora da frase inicial desse texto, durante a pesquisa muitas reflexões sobre a própria experiência foram enunciadas pelas novatas travestis. Diferentes histórias foram contadas nas entrevistas a respeito das formas de se transformar, a partir de seus corpos, ainda iniciantes, no processo de experimentação. Nos enunciados é possível perceber uma inesgotável reflexão e construção de sujeito ao tomarem a si mesmos como objeto de elaboração, ou seja, sua própria corporalidade como elemento a conhecer.

Nesta seção, que pretende discutir o corpo como saber e prática de si, os termos corporalidades e corpos aparecem como ferramentas conceituais importantes, para que pensemos as travestilidades. Nesse sentido, esclarecemos que as corporalidades ora pensadas não se localizam apenas no corpo. Não se situam no corpo substantivo e representacional, mas como menciona Sônia Maluf (2002) - no corpo transformado -, em seu processo de criação e recriação cotidianas. Trata-se, portanto, de corporalidades que conduzem e dão sentido às experiências, permitindo que a natureza do corpo seja exatamente a sua fabricação por meio da intervenção do desejo. 
Na mesma direção, o sentido de corpo apresentado pelo discurso das travestis não se trata de uma superfície de inscrição, mas espaço de criação e, portanto, de sobrevalorização. Ao tomar a experiência trans, observamos que o corpo ocupa destaque e, em alguns discursos, é o que possibilita o sujeito existir dentro ou fora de alguma categoria.

Assim, não tomamos o corpo como contorno, referimo-nos ao corpo que é possível de ser construído e objetificado. Aquele que não está no detalhe anatômico e dispara em multiplicidades, o que cabe aproximar à noção de multidões proposta por Paul Preciado (2011), ao se opor aos corpos que repousam em identidades naturais (homem/mulher) e em práticas sexuais (heterossexual/homossexual). Para o autor, analisar as experiências corporais como multidões é falar "sobre uma multiplicidade de corpos que se levantam contra os regimes que os constroem como normais ou anormais", ou seja, pensar os corpos que tentam a fuga aos ideais cisheteronormativos $^{2}$ (Preciado, 2011, p. 16).

Tentar escapar às normas regulatórias é, de certa forma, questionar as regras, fundamentadas na diferença sexual como diferença material, as quais pretendem normalizar os corpos. É também interpelar uma espécie de genitalização dos modos políticos e econômicos de vida e, bem como das subjetividades. Sobre isso é importante lembrar a detalhada discussão feita por Thomas Laqueur (2001), ao analisar o império da biologia e sua soberana produção de verdades sobre nosso sexo, corpo e sexualidade. $\mathrm{O}$ autor descreve as condições que possibilitaram que os fatos fisiológicos do corpo e a anatomia sexual distinta fossem tomados como a verdade natural sobre os indivíduos. Em outras palavras, trata-se das tramas que propiciaram a primazia da diferença sexual como um discurso construído, uma história da diferença que produziu e produz a essência, o saber sobre os sujeitos, seus corpos e as relações de si mesmo e com os outros.

Historicamente é possível perceber que a partir do saber sobre o sexo dos indivíduos, a sexualidade passou a ganhar centralidade na compreensão da organização da sociedade (Louro, 2004) e, a partir da diferença sexual, apresentou-nos o desenho dos modos como o corpo foi se tornando campo de saber. Para Foucault (2002b), diferente de conhecimento, o saber é um processo pelo qual o sujeito do conhecimento (racionalizado), ao invés de ser fixo, sofre uma modificação durante o trabalho que ele efetua na atividade de conhecer. Deste modo, o saber implica, ao mesmo tempo, uma relação com os objetos de conhecimento, que o autor chama de movimento de objetivação e, consigo mesmo, chamado de processo de subjetivação. Nessas relações toma-se em conta a maneira pela qual se exige que os sujeitos produzam discursos sobre si, a fim de que façam da própria vida um objeto de muitos saberes.

Este corpo sexuado, agora tomado como arena de saber e lutas discursivas, é atravessado pelo poder, um regime que age e incide sobre os corpos invisivelmente. Michel Foucault (1976/2007b), ao tratar do poder sobre os corpos sexuados, afirma que a autoridade de um "saber sobre" com o peso da verdade delegou ao corpo o status de profundidade, tornando-o alvo de exploração. Autorizando-o a ser persistentemente vasculhado e definido. Eis aqui o encontro entre a diferença sexual e o poder sobre os corpos, pois com a diferença sexual sendo percebida como marca da verdade, será no corpo que irão incidir dispositivos disciplinares que visam, sobretudo, seu aprisionamento. Judith Butler (1993/2010a), amplia o debate ao afirmar que o "sexo" ${ }^{3}$ não apenas funciona como norma, mas como parte da prática regulatória que produz os corpos que governa, pelo poder de produzir, demarcar e diferenciar àqueles a quem controla.

Nas palavras de Hélio Cardoso Júnior (2005), a disciplina dos corpos constitui um domínio de técnicas que almejam adestrá-los, a fim de cotizá-los para diversas funções e sob diferentes campos do saber. Inspiradas nesta discussão, fugir às normas pareceu-nos difícil, assim como as frestas para fuga cada vez mais estreitas. Questionamos então: há possibilidades para que os corpos se revoltem contra o poder?

Nas pistas da lógica de pensamento foucaultiana, sim, pois o espaço à fuga também se produz e é analisado por Foucault (1979/2008), ao mencionar a existência de possibilidades de resistência dos corpos à disciplinarização. Espaços nos quais os corpos podem escapar dos dispositivos que se veem perfurados, questionados e tornados ineficientes, sendo esta cruzada, também, um dos efeitos do poder.

Aliadas a esta ideia de revolta dos corpos contra o poder, somos provocadas a pensar que, ainda que o poder esteja penetrado e exposto no próprio corpo, se abrem brechas para fuga. Mais do que isso, ao dependerem de um conjunto de técnicas que objetivam a normatização e a normalização, os corpos demonstram que esta forma ideal é, forçosamente, materializada através do tempo. Segundo Butler (2006), norma não é o mesmo que regra ou lei, ela opera dentro das práticas sociais como algo padrão e "natural", por isso nem sempre de forma explícita. Não em vão sua 
materialização, ou seja, a normatização em seu princípio normalizador de sujeitos é difícil de ler e discernir, sendo apenas sentidos os seus efeitos. O exercício constante de reiteração e repetição da normatização denuncia sua falsa naturalidade e a inconformidade dos corpos. Nestas repetições, o que se estabelecem, além das normalizações, são as possibilidades de espaços entre subjetividade e agenciamento (Butler, 1993/2010a).

Nestes espaços, produzem-se as multidões de diferenças que vão se constituindo nos entre-fluxos, as quais Preciado (2011, p. 14), sinaliza que não são "um tipo de margem ou reservatório de transgressão" em oposição às estratégias identitárias. O que a existência das multidões torna necessário admitir é que os corpos não são mais dóceis.

Até então, ao discorrermos sobre a maneira pela qual entendemos corpo, diferença sexual, poder-saber e a potência dos corpos revoltosos, apresentamos os contornos epistemológicos que nos guiam nos encontros com os processos de experimentações das travestis iniciantes. Essa contextualização teórica permite associar as experiências das jovens iniciantes, não apenas aos corpos revolucionários ou aos docilizados pelas normas, mas também aos corpos das multiplicidades, nos quais Preciado (2011, p. 18) afirma que "não existe diferença sexual, mas uma multidão de diferenças, uma transversalidade de relações de poder, uma diversidade de potências de vida".

Sendo assim, o corpo é um dos principais lócus de convergência nos quais os processos se produzem e legitimam a travestilidade, assim como as corporalidades não se restringem ao corpo-identidade. Também não se limitam ao corpo unitário que aprisiona subjetividades sobre algum território, mas àquele que é agência e experiência de sexualidades. Segundo Anne Damásio (2011, p. 213), é o corpo que é projeto onde sexo, gênero e sexualidade se encontram em uma materialização, que não esgotam o "repertório de composições corporais possíveis", formas desautorizadas de uma (re) invenção de si como problematizaremos a seguir.

\section{Aprendendo a fabricar-se}

Durante os meses de encontro com as jovens travestis em atividades de uma organização não-governamental e em entrevistas na pensão onde residiam, inquietava-nos saber a maneira como elas aprendem a se tornar travesti e, principalmente, como as novatas se articulam entre os discursos de verdade que as definem como sujeitos de tal experiência. Neste exercício de elaboração, foi possível perceber que a experiência trans passa por rituais, processos e critérios, muitas vezes, hierárquicos, com códigos e regras que apenas após serem incorporados podem conferir a quem busca a legitimidade travesti. É a constituição de um campo de experiência tal como Foucault (1984/2006) entende, constituído por jogos de verdade e relações de poder, na relação do sujeito consigo mesmo e com os outros.

Durante as observações participantes, compreendemos que cada uma das jovens travestis construía sua própria história e estratégias de legitimação, ou seja, as relações políticas que engendram o seu reconhecimento dentro e fora do universo trans.

Percebemos, também, que mais do que conhecer os aprendizados que produzem as travestilidades, era necessário interrogar-nos sobre os modos pelas quais as travestis iniciantes buscam acessar a legitimidade. Questionar sobre quais passos é preciso perseguir até que haja reconhecimento, e quais trabalhos sobre si são necessários para que se alcancem os critérios estéticos. $\mathrm{E}$, enfim, como remeter a um conjunto de práticas a verdade sobre sua existência.

De acordo com Foucault (1984/2006), saber de si é ocupar-se consigo mesmo a partir das relações de poder e saber que dão nome e forma à experiência do sujeito, produzindo discursos que conferem algo próximo à natureza e à essência. No caso das jovens travestis, trata-se do acesso aos manuais, às regras e aos passos, que ensinam os modos de ser e as práticas que produzem o sujeito da travestilidade.

A partir dos relatos e entrevistas, foi possível perceber que as jovens travestis acessam estas práticas e saberes por meio da relação com os outros - com outras travestis e com as ferramentas virtuais - onde circulam as informações sobre as técnicas corporais, as facilidades, dificuldades e os rituais de se tornar travesti. Além disso, também é possível o acesso ao saber nas relações consigo, estabelecidas pelas novatas com o próprio corpo e na relação com o desejo, pois seu corpo se torna sua própria experiência e seu principal meio de tornar-se travesti. Ao acompanharmos os rituais e as hierarquias que compõem a construção corporal, a supremacia dos hormônios e dos silicones quase sempre é citada, bem como suas doses, etapas e efeitos esperados.

Deste modo, é possível aproximarmos as técnicas corporais das travestis iniciantes aos escritos contidos nos manuais de instruções que acompanham, não apenas os produtos de consumo e as maneiras de como operá-los, 
mas também o resumo de alguma ciência ou arte como em um livro de ritos. Esclarecemos, com esta pesquisa, que não partilhamos da ideia que existem etapas sistemáticas e fases hierárquicas para tornar-se travesti. Ainda que, em muitas falas, as travestis reconheçam que existam passos que operam como requisitos básicos - como o hormônio e silicone -, percebemos como múltiplas as possibilidades de se experienciar as travestilidades.

Pensamos esse caminho trilhado pelas travestis como o disciplinamento que rege as práticas ascéticas na atualidade. Como ascese, Foucault (1981-1982/2010) definiu um conjunto ordenado de exercícios disponíveis, recomendados e até obrigatórios e utilizáveis pelo homem, para refletir sobre si mesmo e se reconhecer como homem de desejo (Foucault, 1984/2007a). Assim, trata-se das formas pelas quais os gregos praticavam um exercício de si no pensamento, que implicava em um processo de subjetivação e, desta forma, no que o autor vai chamar de práticas de si. Práticas estas que são um cuidado de si pautado em esquemas em que o indivíduo encontra na sua cultura, experiências e técnicas que o ajudam a operar sobre si mesmo.

Para Richard Miskolci (2006, p. 682), tal processo tem consequências subjetivas, já que a subjetividade está diretamente associada à materialidade do corpo, e "a história da criação de corpos é, também, uma história dos modos de produção da subjetividade". Neste sentido, percebemos que as regras que regem o processo de se tornar travesti vão muito além das técnicas corporais e alcançam as formas como as travestis serão compreendidas. Como elas, as técnicas também passam a fazer parte do processo de legitimação e da maneira como entendem o mundo ao seu redor a partir da experiência do corpo.

Trata-se de algumas técnicas do que Francisco Ortega (2008) definiu como biossociabilidade, com regras de cuidados corporais, médicos, higiênicos e estéticos. Dentro desta perspectiva regulatória dos corpos normais e saudáveis, cabe a cada novata ser responsável pelo "autocontrole, autovigia e autogoverno" (Miskolci, 2006, p. 682), pois uma das garantias de sua legitimidade também está associada à sua capacidade de autodisciplina, às normas prescritas pelas travestis mais velhas e pelos sites. Enfim, pelos manuais que produzem as regras as quais Foucault (1984/2006) chamou de jogos de verdade. Jogos em que não se descobrem coisas verdadeiras, mas as regras que fazem algo se confirmar como verdadeiro ou falso.

Conforme foi mencionando no início do artigo, parte desta pesquisa foi realizada durante visitas a casa de quatro jovens travestis que residiam juntas, em regime de pensionato, com uma travesti mais velha e experiente. Com elas foi possível conhecer os códigos e gírias utilizadas nessa seção, bem como acompanhar o processo de ensino e aprendizagem corporal e social que envolve a relação entre "mãe" e "filhas", uma forma encontrada pelas jovens para nomear quem as ensina à construção corporal e a maneira como se percebem dentro do processo de fabricarem-se.

Antes de analisarmos os passos, rituais e receitas para alcançar o que as jovens reconhecem como travestilidade, algumas cenas do diário de campo são recuperadas, aqui, por sua importância para a discussão:

"De um lado do quarto uma jovem escovava a peruca; sentada na cama, a outra telefonava para os clientes mais habituais. Uma delas, ao mesmo tempo em que conversava comigo, conduzia-me à cozinha, onde retira uma sacola da gaveta da pia e despeja seu conteúdo em cima da mesa. Muitas cartelas de medicamentos caíram, segundo ela, um coquetel e, como numa prescrição médica, descreveu as dosagens que fazia com aqueles anticoncepcionais: 'uma vez por mês coloco uma cartela inteira no liquidificador e misturo com água, tomo um copão. No resto do mês tomo uma pílula de cada cartela todos os dias'. Pergunto como aprendeu, ela me disse que foi testando as alterações em seu corpo, e continua "uso também o contraceptivo injetável e o adesivo no braço".

Exibiu-me a parte interna no braço e contou-me que, com isso, os quadris aumentaram (levanta a blusa), os seios cresceram (aperta um deles com a mão), a voz ficou um pouco aguda (mesmo ainda grave, diz gostar como está), e a bunda se espalhou. Mesmo assim, achou necessário acrescentar silicone líquido na bunda, e, expressando dor, seguiu-me relatando: 'foi a pior dor que senti, aquele líquido desce queimando e elas $^{4}$ massageiam, gritei muito! Só depois disso entendi a dor que as mais velhas falam. Acho que compreendo a implicância delas com a gente'".

Com essa cena, adentramos no terreno do desejo nas travestilidades. O terreno dos hormônios e silicones, da valorização dos corpos e da centralidade que eles ocupam na discussão das experiências trans.

Em diálogos com travestis experientes ou novatas e na leitura de literatura especializada sobre o tema no Brasil (Benedetti, 2005; Duque, 2005; Kulick, 2008; Pelúcio, 2005; 2007;Silva, 2007; 2006), percebemos que a fórmula básica mencionada, não apenas como regra, mas como ritual entre as travestis, é a experimentação do hormônio circulando no sangue e o silicone penetrando na carne. 
Segundo o historiador James Green (2000), os hormônios são usados pelas travestis desde o final da década de 1960, e tiveram sua importância citada na pesquisa de Hélio Silva (2007, p. 170), realizada no início dos anos 1990. Considerada por este autor não apenas como a poção do contorno corporal, mas também da formação de uma moral, de um caráter. Alguns anos depois, Marcos Benedetti (2006, p. 16-17) também discutiu a centralidade do hormônio para a construção da travestilidade, pois "é essa substância que, ao misturar-se ao sangue, instaura uma nova condição no corpo: a condição de travesti".

É possível perceber, quando analisada a literatura produzida sobre mulheres trans, que o uso do hormônio continua uma tendência entre as travestis. Mais do que isto, sua importância traz à cena sua função de (re) criação, de manutenção e de garantia de feminilização ao agir sobre os corpos. Inaugura o saber, as técnicas e a engenhosa manipulação dos líquidos, comprimidos e adesivos que moldam a existência de um novo sujeito.

Atualmente, são variadas as técnicas à disposição não apenas das travestis, mas de qualquer pessoa que busque conformar-se aos padrões estéticos e cultural historicamente estabelecidos. Em sua maioria, esse conjunto de técnicas é destinado a quem deseja esculpir-se sob os modelos de beleza hegemônicos: embranquecer, alisar, emagrecer e rejuvenescer.

Conforme o trecho extraído do diário de campo no início desta seção, percebemos a importância dos hormônios para as travestis, assim como o ritual, o aprendizado, a testagem e a comprovação das técnicas como formas de desvendarem-se a si mesmas no que envolve sentir o hormônio invadindo as superfícies do corpo.

Durante as visitas na pensão das jovens travestis, foi possível registrar, ainda, relatos sobre desmaios quando doses altas de hormônios foram ingeridas em jejum pelas novatas travestis. Altas dosagens são ingeridas entre as que se prostituem, pela urgência da feminilização do corpo, pois, segundo algumas, isso garantiria a elas uma maior aceitação por parte da clientela.

Foi possível, então, identificar algumas relações estabelecidas entre o uso dos hormônios e o sustento financeiro. $O$ primeiro é associado às iniciantes que se prostituem, pois estas acreditam que os hormônios garantem uma procura maior dos clientes que valorizam a feminilidade, além de considerarem que os hormônios agem melhor em seus corpos por elas serem jovens. Por isso fazem uso da substância cada vez mais cedo.
Porém, entre as iniciantes que não buscam a "pista" como forma de sustento, outra relação parece se estabelecer entre os hormônios e o trabalho. Estas dizem não desejar fazer uso antes de terem um emprego fixo. Uma delas expressa sua opinião a respeito do uso dos hormônios: "Já é difícil conseguir emprego como gayzinho homem, imagina como travesti? Não, não quero hormônio agora!"

Em relação às jovens que não querem, no momento, fazer uso de hormônios, percebe-se que estas não estão no mercado do sexo, e por isso não demonstram ter a mesma urgência daquelas que estão, cotidianamente, disputando a aceitação dos clientes. Também não fazem parte da concorrência por espaço territorial na pista, que depende, inclusive, da aceitação das mais experientes no local - quanto mais feminina, mais respeitada se é neste espaço.

A segunda questão que levantamos sobre novatas que recusam o uso dos hormônios, tem íntima ligação com seus corpos, uma vez que todas as jovens entrevistadas exibiam um corpo considerado privilegiado entre as trans. Tanto as travestis que conhecemos no escopo da pesquisa, quanto a jovem citada por Tiago Duque (2009), em sua dissertação, como uma novata que não deseja se hormonizar, exibem corpos considerados pelas demais como "femininas por natureza". $\mathrm{Na}$ pesquisa do autor, a iniciante também menciona as poucas possibilidades de trabalho como um dos impeditivos para aderir a hormonização.

Outro ponto sobre os hormônios diz respeito à instabilidade emocional que as travestis mais experientes e também as mais jovens relatam sentir. Comentários como "eles nos deixam atacadas" ou "as travas ficam tudo loucas" foi comum entre aquelas que faziam uso de hormônios. Contudo, o que chama a atenção é a relação feita entre os sintomas de irritação e a falta de controle emocional com a circulação de características femininas pelo corpo hormonizado. Em outras palavras, a alteração de humor é considerada um sintoma que as posicionaria, ainda mais, no universo da natureza feminina (Benedetti, 2006; Damásio, 2011; Kulick, 2008; Pelúcio, 2005; Silva, 2007). Um modelo essencialista que atribui às mulheres a "doença dos nervos" e os sintomas da natureza uterina.

Para além dos hormônios, percebemos nas entrevistas que, atualmente, as travestis conseguem acessar mais facilmente outras tecnologias que auxiliam na feminilização, tais como depilações, implantes, raspagens, entre outras inúmeras técnicas do que Preciado (2008) chamou 
tecnocorpo. Para elaborar este termo, o teórico queer baseou-se na ideia do tecnopoder discutida por Donna Haraway (1991) como uma forma de tecnologia de gênero que codifica, descodifica, programa e desprograma. São estratégias sintéticas, maleáveis, suscetíveis de serem transferidas, copiadas, produzidas e reproduzidas tecnicamente pelos sexos e gêneros dos "bio" e "tecno" sujeitos.

Pelos caminhos desta rede tecnológica, outro investimento considerado importante no reconhecimento das travestilidades é o uso do silicone em composição líquida, podendo ser injetado em diferentes partes do corpo. Juntamente com a hormonização,

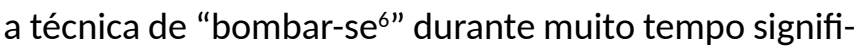
cou a entrada definitiva no mundo das travestis (Pelúcio, 2009). O procedimento é realizado pelas bombadeiras, travestis que se especializam em aplicar silicone líquido clandestinamente nas outras. Acreditamos que um dos maiores efeitos já relatados sobre o silicone líquido, além da forma rápida que dá ao corpo, são as dores que elas narram sentir. Pelas entrevistas, percebemos que as travestis que fizeram uso das injeções dificilmente esquecem a queimação do líquido que parece rasgar a pele invadindo a superfície cutânea. Uma espécie de invasão consentida que "corrige" o biológico e marca o ritual de entrada do novo corpo.

A sensação de dor tornou-se uma das características de legitimidade entre as travestis, as dores da beleza como são conhecidas e as formas de resistir são citadas por Pelúcio (2009, p. 232). As dores são compartilhadas, e são dores públicas que anunciam a iniciação da novata. Há a expectativa de que ela passe por isso para se tornar travesti, e não mais o viadinho, o gayzinho. Quanto mais a travesti conhecer na carne os efeitos dessa adesão, mais os terá na alma.

Entretanto, entre as iniciantes entrevistadas, poucas relataram terem recorrido a este procedimento, discurso que também apareceu nos achados da pesquisa de Tiago Duque (2009) com travestis adolescentes no interior de São Paulo. Mesmo as novatas que contaram ter realizado aplicações de silicone líquido, disseram ter feito na bunda e nos quadris, mas jamais fariam nos seios. Compartilhamos da mesma ideia do pesquisador de que o imperativo de bombar o corpo talvez tenha perdido um pouco sua força entre as mais jovens, e nos levam a apontar alguns possíveis motivos desta decrescente adesão ao procedimento.

Além da própria dor que, segundo as jovens travestis, tem sido pouco glamourizada entre a nova geração, a justificativa que mais apareceu entre as novatas que rejeitam o uso deste tipo de silicone, tem relação com o discurso da saúde. Foi citado por elas o medo e até mesmo o exemplo de mortes de travestis conhecidas em decorrência das complicações do silicone líquido. Relatam o temor de que ele "escorra" para o coração, como acreditam que pode acontecer quando injetado nos seios.

Atualmente o silicone, na forma líquida, tem sido alvo de preocupação de algumas políticas públicas de saúde $\mathrm{LGBT}^{7}$ e de redução de danos (Duque, 2005; 2009) frente aos perigos de infecções, devido às grandes perfurações realizadas na pele. E, principalmente, pelas chances de "descer" para outras regiões do corpo obstruindo órgãos vitais.

Ainda sobre o uso do silicone líquido, a rejeição das jovens parece também estar associada à questão de classe, por ser considerado entre as iniciantes um recurso utilizado pelas travestis mais pobres, ou por aquelas que se prostituem e, por isso, precisam acessar as formas corporais mais depressa. No mesmo sentido parece ter relação também com status, pois as travestis "tops", como muitas novatas desejam se transformar, asseguram que não têm nem nunca terão esse "lixo" no corpo (Pelúcio, 2009).

Sejam guiadas pelo medo da morte, pela garantia de saúde, pela condição financeira, status ou pela pressa ou não em "botar corpo" como mencionaram algumas jovens, o fato é que a adesão às próteses de silicone e não mais ao líquido injetável parece ter sido maior nestes últimos anos. Algumas jovens participantes da pesquisa afirmaram que estavam juntando dinheiro para pagar suas próteses e, enquanto não as têm, recorrem à antiga prática do enchimento no sutiã.

Além do tempo e investimentos necessários para seguir o processo de transformação inicial, há uma passagem simbólica muito intensa neste processo. Inicia-se uma espécie de rito no qual as novatas vão se posicionando cada vez mais próximas da categoria "travestis de verdade", em que vão, aos poucos, tateando o tornar-se travesti e adquirindo legitimidade neste espaço que valoriza o corpo fluido, mas em sua condição duradoura, portanto, na carne e nos nervos.

Ao entrevistar as jovens travestis durante atividades em uma ONG, entendemos que o retorno do uso de enchimentos, a diminuição pela procura do silicone líquido e a espera um pouco mais paciente pelas próteses, em alguns casos, também parecem aproximar-se das questões que envolvem as idades das novatas. 
Consideramos o fato de que algumas jovens, pela pouca idade, convivem com a intolerância dos pais e ainda residem com eles, não possuem dinheiro muito menos autonomia para transformarem seus corpos com o uso de hormônios e silicone. Entra em discussão o que Tiago Duque (2009) intitulou "montagem estratégica", realizada por aquelas novinhas que não podem se montar conforme seu desejo. Para o autor, trata-se de uma nova relação com o dispositivo do armário, em meio às exigências de um universo social, pois as novatas se montam e desmontam apenas em locais em que é permitido, longe dos familiares e entre amigas. Assim, esta montagem tornou-se um modo de fabricação de si, de quem busca se proteger das violências, sendo também a possibilidade de sobrevivência que algumas têm encontrado para esconderem de seus familiares o que não passa, apenas, pela desconfiança acerca da sua homossexualidade, mas pela descoberta da travestilidade.

No relato das entrevistadas, vislumbramos a montagem estratégica quando uma das jovens descreveu como mantinha suas roupas e maquiagens escondidas na casa das "irmãs", modo como chamava os amigos gays vizinhos de bairro. As amigas entre $13 \mathrm{e}$ 17 anos se reuniam, à tarde, no quarto de uma delas, para se montar e tirar fotos. Quando tinham a oportunidade, fugiam de casa para irem montadas às festas, longe do bairro. Segundo ela, com medo de que a mãe descobrisse, antes de voltar para casa, todas trocavam a roupa e removiam a maquiagem.

Podemos perceber que, na montagem estratégica, as novatas começam a se montar e desmontar com maior facilidade. É desta maneira que algumas jovens têm experienciado a travestilidade dentro de seus quartos, até o momento de conseguirem conquistar o mínimo de aceitação dos pais ou autonomia financeira para saírem de casa. Acessórios facilmente removíveis, como as perucas, por exemplo, que foram em outras épocas utilizados e, hoje, foram abandonados pelas mulheres trans, ao que tudo indica, estão retornando como um modo de sobrevivência para algumas, especialmente aquelas que ainda transitam em espaços escolares e familiares hostis.

A estas possibilidades de transgressão, até mesmo dos ideais hegemônicos da travestilidade, aproximamos o que Preciado em entrevista a Jesús Carrillo (2007) denomina como um tipo de incorporação desviante às tecnologias de gênero. Tecnologias estas entendidas por Lauretis (1994) como uma maquinaria de produção de discursos, que apoiados nas instituições do Estado (escola, família, por exemplo) produzem as categorias de gênero pelas quais seremos interpelados como homens ou mulheres.

Contudo, no que diz respeito às tecnologias de gênero, o interesse de Preciado (Carrillo, 2007) está nas suas possibilidades de falhas, pois o desvio e a transgressão a elas denunciam que há uma citação descontextualizada e um uso impróprio das tecnologias de normalização. São produzidas, assim, as descontinuidades e os modos de subverter seu uso, os quais Pelúcio (2009, p. 90) relaciona à utilização que as mulheres travestis fazem da tecnologia protética e hormonal para transformarem seus corpos. Para a autora, as travestis denunciam com isto, ainda que sem tal intencionalidade, possíveis apropriações não planejadas dessas tecnologias, e é neste sentido que as tecnologias de gênero falham e são reapropriadas.

Para conhecer as técnicas e rituais do que parece um manual de instruções, e sobre um fazer de si a mais verdadeira e legítima possível, perguntamos às jovens sobre quem as ensina, e como elas têm acesso a essa engenharia corporal e social do que desejam como travestilidade. Diferentes formas de acessar esses saberes foram relatadas pelas jovens. Entre as iniciantes que se prostituem, a sociabilidade com a "mãe" e as "irmãs" mostrou-se um processo conjunto de descobrir, experimentar, comprovar e partilhar as transformações corporais e sociais. Com elas entendemos que as mães ou madrinhas são travestis mais experientes. Algumas são cafetinas, bombadeiras, donas-da-rua ${ }^{9}$ e da pensão, mas não necessariamente, pois elas também podem ser uma amiga que oferece abrigo, indica a melhor bombadeira, o tipo e a quantidade de hormônios necessários para a fabricação corporal.

Entre as participantes dessa pesquisa, a mãe-travesti era quem alugava quartos na pensão e ensinava jovens inexperientes iniciarem-se na prostituição e, desta forma, aprenderem a construir seu próprio corpo. Cada jovem pagava diárias, e, nesta lógica de funcionamento, os comportamentos e os modos de se transformarem corporalmente seguiam regras sistemáticas estabelecidas pela mãe que, através da experiência, conhecia o que era preciso para tornarem-se travestis de verdade. Uma relação de ambivalência construída entre carinhos e lucros, além da vigilância da mãe em torno do uso de drogas, da prevenção às doenças sexualmente transmissíveis e à quantidade certa de hormônios, maquiagem e silicone. Nas palavras da mãe, é necessária uma "disciplina militar", para um dia serem reconhecidas como travesti pelas mais velhas. 
Não é difícil percebermos que o olhar atento da mãe, madrasta ou cafetina está em todo lugar, do mesmo modo que Pelúcio (2009, p. 208) observou em sua tese: "seu papel organizador é ramificado na rede das travestilidades. Atua na rua, na casa e nos corpos. É tanto aquela que explora e até maltrata, quanto a que cuida".

Partilhar por três meses momentos de convívio nessa pensão permitiu-nos entender também a sociabilidade das irmãs, uma cumplicidade entre jovens com pouco conhecimento sobre os modos de transformarem-se. Mesmo com entradas e saídas semanalmente negociadas com a dona do local, percebemos nestes momentos entre elas laços intensos em "amizade, jocosidade, conflitos, disputas, moralidades e hierarquias", descritos por Fernanda Cardozo (2009, p. 56) como algumas das "socialidades"10 entre as travestis. Para, além disso, a pensão nos pareceu ser o lugar em que se legitimar como travesti era encarado como imperativo, mas também um dos poucos espaços onde alcançar isso era uma empreitada coletiva, e por vezes, também prazerosa.

Já entre as jovens que não se prostituem e, portanto, não têm acesso a uma mãe, madrinha, cafetina ou a irmãs, as informações e passos para conhecerem e experienciar as travestilidades estão na internet, sendo acessadas, clandestinamente, em seus quartos. Para muitas, o quarto e a internet são os únicos espaços em que podem pensar em existir enquanto travesti.

Tanto sozinhas ou com amigas, as iniciantes relatam circular pelos blogs, sites e perfis do Facebook para se sociabilizarem e trocar informações acerca dos processos de transformação. Segundo elas, os blogs, diários virtuais destinados às travestis que estão começando, indicam formas de se vestir, maquiar e comportar. Também encontram indicações de hormônio, além de apresentarem imagens de padrões a serem seguidos e dicionários que explicam as gírias usadas entre as travestis.

A partir da função exercida pelas ferramentas virtuais, percebemos uma substituição do papel das mães e cafetinas nos ensinamentos e manutenção das travestilidades. Inclusive, compensando a falta delas, se for levada em consideração a experiência de jovens que se montam às escondidas ou recorrem à montagem estratégica. Os espaços virtuais vêm sendo utilizados, entre outras coisas, para a difusão de informações e trocas entre travestis de diferentes idades e experiências, que encontram na virtualidade um espaço para perguntar, desabafar ou simplesmente acompanhar anonimamente o que é postado por outras travestis.
Ao passear pelos blogs especializados, tais como "Casa de Bonecas" e "Czinhas do Brasil", chama a atenção o discurso normativo que é produzido, em uma relação incontestada de binarismos de gênero e normalização dos corpos. Nas imagens utilizadas, percebemos uma semelhança, cada vez maior entre os padrões corporais e o antigo apelido "boneca", dado às travestis. Não em vão, uma imagem frequente nestes ambientes é a da boneca Barbie, como referência feminina de beleza, magreza e delicadeza.

Para Tiago Duque (2009), estas novas referências estéticas das travestilidades, por serem muito diferentes daquelas que foram disseminadas pelo mercado do sexo, expressam que um dos efeitos do poder sobre estes corpos está na cautelosa nova modelagem, no intuito de posicioná-las melhor nos espaços de legitimidade e de padrões sobre os modos produzidos como corretos, normais e saudáveis de existir. São feminilidades construídas de acordo com os contornos de uma nova imagem, que garantiria respeitabilidade nos espaços formais, tornando-as delicadas, menos escandalosas, mais comportadas, menos vulgares. Subversão e assujeitamento fazem-se presentes aqui, ainda que pareçam paradoxais (Pelúcio, 2009, p. 112).

Se novas formas de travestilidades estão sendo produzidas junto com os novos padrões estéticos, podemos dizer que está sendo produzido, também, um novo feminino, bem como novos modos de se experienciar o tornar-se travesti e os critérios que o legitimam. Afinal, se a experiência trans é seu próprio corpo, segundo Butler (1990/2010b), suas transformações corporais falam, portanto, da materialização de um gênero.

Consoante Preciado (Carrillo, 2007), esta materialização é possível a partir da reiteração de normas que prescrevem o que é ser feminina e pelas quais, performativamente, atuam as disciplinas e tecnologias biopolíticas como máquinas para naturalizar o sexo. São tecnologias legitimadas por discursos em que as travestis também são alvo, há muito tempo, passando pelos saberes médicos, farmacêuticos, psicológicos e midiáticos na busca por intervenções cirúrgicas e químicas (hormonais) que visam, sobretudo, adequar os sexos e torná-los inteligíveis a partir de uma matriz cisheteronormativa (Pelúcio, 2009).

Ainda assim, as jovens iniciantes não se tornam inteligíveis, uma vez que o olhar vigilante das outras travestis parece apontar para seus corpos em processo. Com as jovens novatas, percebemos que a condição de "quase" travesti as mantém em uma zona pouco 
legítima, a tal ponto de não serem reconhecidas como sujeitos legítimos das travestilidades.

Muitas participantes desta pesquisa relataram violências, xingamentos, apelidos ofensivos e discriminações de diferentes tipos por parte das travestis mais experientes, que, segundo elas, sentem-se autorizadas a agirem com hostilidade, por acreditarem que a experiência, a idade, e o maior tempo de pista e transformações lhe conferem poder sobre as mais jovens. As jovens narraram dificuldades em se defenderem das agressões das mais experientes, que pertencem a um mundo ainda pouco conhecido para novatas que estão começando. Trata-se de realidade na qual circulam gírias e negociações, além dos desagradáveis apelidos que cercam sua transformação, considerada pelas mais velhas como inacabada e, por vezes, vista como inumana e, portanto, abjetas, como mostram os apelidos Transformers e Pokémon, dado a elas em uma clara associação aos seres não humanos.

Segundo Butler (1993/2010a, p. 19-20), "os abjetos são as zonas invisíveis, inabitáveis da vida social que estão densamente povoadas por quem não goza da hierarquia dos sujeitos". Esta não existência no campo social acaba por colocar sujeitos como as jovens travestis iniciantes no plano do abjeto, tornando-as sujeitos cuja existência parece não importar. De fato, importam, pois os abjetos precisam estar lá, ainda que numa higiênica distância, para demarcar as fronteiras dos sujeitos da normalidade.

Em conversas com travestis experientes, compreendemos que as dificuldades e rejeições impostas às mais jovens, não são regra geral. Esse distanciamento ou até mesmo a violência exercida por algumas parece colocar em questão não apenas uma legitimidade trans, mas também disputas em torno da idade, das condições financeiras e valores ligados à beleza e ao status social. Assim, experienciar outras formas de travestilidades pode parecer às mais velhas uma desvalorização ou abandono dos seus antigos movimentos de resistência e, por isso, formas pouco legítimas de se tornar uma travesti de verdade.

\section{(In)conclusões}

Com a pesquisa, percebemos que as jovens iniciantes aprendem, criam e recriam formas de fabricarem seus corpos e a si mesmas por ousadas, ou até mesmo, normativas formas de existência, no intuito de alcançarem o que reconhecem como travestilidade. No entanto, a importância em mantê-las em uma zona de não-existência, como figuras não-reconhecidas, inclusive entre as próprias travestis, garante os contornos do que pode ser considerado como normal, inteligível e vivível. Para Butler (1990/2010b, p. 39), são exatamente essas possibilidades outras de configurações das identidades de gênero, falhas, descontínuas, subversivas e ilógicas do ponto de vista da matriz cultural cisheteronormativa, que "criam oportunidades críticas de expor os limites e os objetivos reguladores desse campo de inteligibilidade". Subversivas ou não, o fato é que a própria experiência trans, em si mesma, denuncia a pretensa naturalidade dos sexos e da heterossexualidade. Embaralha categorias e se reiventa até mesmo de dentro da própria travestilidade como modo de experiência.

Aliadas às tecnologias e à virtualidade das informações percebemos que as novas travestilidades inauguram atualizados modos de aprender, experimentar e transformarem-se, ainda que preservem o desejo por reconhecimento. Afinal, analisar as práticas de cuidado de si é discutir a maneira como os sujeitos se relacionam consigo mesmos e tornam possível a relação com o outro. Indica, portanto, o conjunto de experiências e técnicas que o sujeito elabora e que o ajuda a transformar-se a si mesmo. Um ideal ético que consiste em fazer de sua vida um objeto de tekhnê, uma obra de arte (Foucault, 1984/2006).

Por meio da (re)invenção de práticas de si e sobre si, as experiências das jovens iniciantes nos fazem compreender que a liberdade de criação persistente, e seus esforços transgressores colocam em tensão, não apenas a naturalidade dos corpos, mas também a experiência das travestilidades, os modos como se produzem o que se conhece, hoje, por travestis e sob que condições são possíveis suas múltiplas formas de existência.

\section{Referências}

Beauvoir, S. (1980). O segundo sexo. Rio de Janeiro: Nova Fronteira. (Obra original publicada em 1949)

Benedetti, M. (2005). Toda feita: o corpo e o gênero das travestis. Rio de Janeiro: Garamond.

Benedetti, M. (2006). (Trans)formação do corpo e feitura do gênero entre travestis de Porto Alegre, Brasil. In C. Cáceres; G. Careaga; T. Frasca, \& M. Pecheny (Orgs.), Sexualidad, Estigma y Derechos Humanos (pp.145-166). Lima: UPCH.

Butler, J. (2006). Regulaciones de género. La ventana, 23, 07-35. Recuperado de https://goo.gl/G9xNcj

Butler, J. (2010a). Cuerpos que importan: sobre los límites materiales y discusivos del "sexo" (2 $2^{\underline{a}}$ ed.). Buenos Aires: Paidós. (Obra original publicada em 1993)

Butler, J. (2010b). Problemas de gênero: feminismo e subversão da identidade (3 $3^{\underline{a}}$ ed.). Rio de Janeiro: Civilização Brasileira. (Obra original publicada em 1990) 
Cardoso Júnior, H. R. (2005). Para que serve uma subjetividade? Foucault, tempo e corpo. Psicologia: Reflexão e Crítica, 3(18), 343-349. doi: 10.1590/S0102-79722005000300008

Cardozo, F. (2009). Das dimensões da coragem: socialidades, conflitos e moralidades entre travestis em uma cidade no sul do Brasil. (Dissertação de Mestrado, Universidade Federal de Santa Catarina, Florianópolis). Recuperado de https://goo.gl/HDNndJ

Carrillo, J. (2007). Entrevista com Paul Beatriz Preciado. Cadernos Pagu, 28, 375-405. doi: 10.1590/S0104-83332007000100016

Damásio, A. (2011). Botando corpo e (re)fazendo gêneros. (Tese de Doutorado, Universidade Federal do Rio Grande do Norte). Recuperado de https://repositorio.ufrn.br/jspui/handle/123456789/22333

Duque, T. (2005). Montadas para toda a vida? O uso do silicone líquido na construção da identidade travesti. (Monografia de Graduação, Pontifícia Universidade Católica de Campinas).

Duque, T. (2009). Montagens e Desmontagens: vergonha, estigma e desejo na construção das travestilidades na adolescência. (Dissertação de Mestrado, Universidade de São Carlos). Recuperado de https://repositorio.ufscar.br/handle/ufscar/6702

Foucault, M. (2002a). A arqueologia do saber. Rio de Janeiro: Forense Universitária. (Obra original publicada em 1969)

Foucault, M. (2002b). A verdade e as formas jurídicas ( $3^{\underline{a}}$ ed.). Rio de Janeiro: NAU editora.

Foucault, M. (2006). Foucault. In M. B. Motta (Org.), Ditos e escritos V: ética, sexualidade e política (pp. 234-239). Rio de Janeiro: Forense Universitária. (Obra original publicada em 1984)

Foucault, M. (2007a). História da sexualidade II: o uso dos prazeres (12 ${ }^{\mathrm{a}}$ ed.). Rio de Janeiro: Graal. (Obra original publicada em 1984)

Foucault, M. (2007b). História da sexualidade I - a vontade de saber (12 ${ }^{\underline{a}}$ ed.). Rio de Janeiro: Graal. (Obra original publicada em 1976)

Foucault, M. (2008). Microfísica do poder (25a ed.). Rio de Janeiro: Graal. (Obra original publicada em 1979)

Foucault, M. (2010). A hermenêutica do sujeito (3를. ed.). São Paulo:Wmf Martins Fontes. (Obra original publicada em 1981-1982)

Green, J. (2000). Além do carnaval: a homossexualidade masculina no Brasil do século XX. São Paulo: UNESP.
Haraway, D. (1991). Um manifesto para os cyborgs: ciência, tecnologia e feminismo socialista na década de 80 . In H. Hollanda (Org.), Tendências e impasses: o feminismo como crítica da cultura (pp. 243-288). Rio de Janeiro: Rocco.

Kulick, D. (2008). Travesti: prostituição, sexo, gênero e cultura no Brasil. Rio de Janeiro: Fiocruz.

Laqueur, T. (2001). Inventando o sexo: o corpo e gênero dos gregos a Freud. Rio de Janeiro: Relume Dumará.

Lauretis, T. (1994). A tecnologia do gênero. In H. Hollanda (Org.), Tendências e impasses: o feminismo como crítica da cultura (pp. 206-242). Rio de Janeiro: Rocco.

Louro, G. (2004). Um corpo estranho: ensaios sobre a sexualidade e teoria queer. Belo Horizonte: Autêntica.

Maluf, S. (2002). Corporalidade e desejo: tudo sobre minha mãe e o gênero na margem. Revista Estudos Feministas, 10(1), 143-153. doi: 10.1590/S0104-026X2002000100008

Misckolci, R. (2006). Corpos elétricos: do assujeitamento à estética da existência. Revista Estudos Feministas, 14(3), 681-693. doi: 10.1590/S0104-026X2006000300006

Ortega, F. (2008). O corpo incerto: corporeidade, tecnologias médicas e cultura contemporânea. Rio de Janeiro: Garamond.

Pelúcio, L. (2005). Toda Quebrada na Plástica: corporalidade e construção de gênero entre travestis paulistas. Campos - Revista de Antropologia Social, 6(1-2), 97-112. doi: 10.5380/cam.v6i0.4509

Pelúcio, L. (2007). Eu me cuido, mona: saúde, gênero e corporalidade entre travestis que se prostituem. Texto completo apresentado em Seminário Homofobia, Identidades e Cidadania GLBTTT, Florianópolis. Recuperado de https://goo.gl/vjvUxM

Pelúcio, L. (2009). Abjeção e desejo - uma etnografia travesti sobre o modelo preventivo de aids. São Paulo: Annablume; Fapesp.

Preciado, P. (2008). Testo Yonqui. Madrid: Espasa Calpe.

Preciado, P. (2011). Multidões queer: notas para uma política dos "anormais". Revista Estudos Feministas, 19(1), 11-20. doi: 10.1590/ S0104-026X2011000100002

Silva, H. (2007). Travestis: entre o espelho e a rua. Rio de Janeiro: Rocco.

\begin{abstract}
1. Os termos travestis e trans são utilizados nesse artigo para se referir às pessoas travestis e transexuais, levando em conta que, no Brasil, adotar essas duas experiências como categorias fixas e diferentes entre si, tal como o discurso biomédico produziu pode ser uma percepção frágil e limitada. Em suas vivências, as travestis e transexuais expõem a precariedade de tal divisão ao borrarem as fronteiras, demonstrando que as categorias envolvem uma multiplicidade de performatividades de gêneros e sexualidades que, nestes casos, extrapolam sólidas definições.

2. Heteronormativo, segundo Butler (1990/2010b), refere-se à ideia de natureza humana que compreende como certezas universais e hegemônicas que os sujeitos são em sua essência, heterossexuais. Esta norma para agir precisa constantemente ser reafirmada, e para isso, é importante que seja aceita como inata e inquestionável, servindo de sustentação para moldar as relações sociais em um padrão binarista. Um esquema hierarquizado das diferenças sexuais em que se organizam os corpos e as práticas em duas possibilidades de existência - masculina ou feminina. Ainda que Butler e Preciado não utilizem em suas obras o termo cisnorma, é possível acrescentá-lo nessa discussão uma vez que a proposta do uso político do prefixo "cis" é utilizado para designar pessoas cujo sexo designado ao nascimento conforma-se à sua performatividade do gênero. Problematizar a cisnorma tem como objetivo denunciar o discurso de naturalização das identidades cis e expor o sistema de privilégios que as mantém como normais, mostrando que elas são tão construídas quanto as identidades travestis e trans.
\end{abstract}

3. Sexo que não se institui apenas como genitália, prática e ato sexual, mas trata-se também de uma economia regulatória. Economia, no sentido foucaultiano, contempla práticas corporais, condutas e, também prescrições, interdições e exclusões.

4. Referência às bombadeiras, travestis especializadas em "bombar", aplicar o silicone líquido.

5. Pista, batalha, quadra, esquina são termos utilizados para se referir à rua como espaço de prostituição. 
Essa Boneca Tem Manual: práticas de si, discursos e legitimidades entre travestis iniciantes

${ }^{6}$ Bombar significa injetar com agulhas o silicone líquido no corpo.

7. Sigla do movimento político e social que abrange lésbicas, gays, bissexuais, travestis, transexuais e transgêneros.

8. As expressões "tops e finas" aparecem como categorias entre as iniciantes quando mencionam o que desejam para si mesmas. São expressões que representam modos de ser, de se produzirem e comportarem-se. Assim como Larissa Pelúcio (2010), compreendemos algumas dessas como um processo que por vezes contribui com o distanciamento das origens de classe, raça/etnia na busca por uma idealizada ascensão social.

9. Travestis que cobram valores para o uso dos espaços de prostituição.

10. Termo proposto pela autora para falar da matriz relacional que constitui as pessoas a partir das relações.

Marilia dos Santos Amaral, Doutora em Psicologia pela Universidade Federal de Santa Cartarina (UFSC), é Professora do Curso de Psicologia da Faculdade Cesusc mantida pelo Complexo de Ensino Superior de Santa Catarina. Endereço para correspondência: Avenida Mauro Ramos, $n^{\circ} 733$, apto 301, bloco A. Edifício Solar do Faial. Centro, CEP: 88020-301. Florianópolis, Santa Catarina. Telefone: (048) 99852 7400. Email: mariliapsico@hotmail.com

Maria Juracy Filgueiras Toneli, Doutora em Psicologia Escolar e do Desenvolvimento Humano pela Universidade de São Paulo (USP), Pós-Doutora em Psicologia Social pela Universidade Federal de Minas Gerais (UFMG) e pela Universidade do Minho (Uminho), é Professora titular na Universidade Federal de Santa Catarina (UFSC). Email: juracy.toneli@gmail.com 